\title{
Postoperative Nausea and Vomiting in Plastic Surgery
}

\author{
Donald W. Buck II, M.D., ${ }^{1}$ Thomas A. Mustoe, M.D., ${ }^{1}$ and John Y.S. Kim, M.D. ${ }^{1}$
}

Postoperative nausea and vomiting (PONV) is a common problem affecting nearly one third of all surgical patients. In addition to making the patient feel miserable, PONV is a major cause of prolonged recovery, unintended hospital admission, and poor patient satisfaction after surgery. Retching and vomiting can also lead to hematoma formation, wound and suture dehiscence, and aspiration. Thus, the prevention of PONV is an important goal in the overall outcome of surgery and, in particular, plastic surgery. The etiology of PONV is multifactorial, and several important risk factors have been identified. These factors include female gender, nonsmoking status, and a history of PONV or opioidinduced nausea and emesis. Volatile anesthetics and long operative duration also increase the risk of PONV. Reduction in the incidence of PONV requires careful assessment of patient-related risk factors as well as the appropriate use of prophylactic antiemetics. There are many antiemetic medications on the market today. Ondansetron, a serotonin 5hydroxytryptamine antagonist, appears to be the current drug of choice for PONV prophylaxis. It has greatest efficacy and cost-effectiveness when used in patients at moderate to high risk. In addition, surgeons can consider using intravenous propofol or conscious sedation instead of general anesthesia where appropriate.

KEYWORDS: Postoperative, nausea, vomiting, emesis, PONV, antiemetic

$\mathrm{P}_{\text {ostoperative nausea and vomiting (PONV) }}$ affects nearly one third of all surgical patients. ${ }^{1}$ It is consistently reported as one of the most unpleasant experiences following surgery. ${ }^{2}$ Hirsch estimated in 1994 that PONV costs a single ambulatory surgical center between $\$ 0.25$ million and $\$ 1.5$ million per year in lost surgical revenue. ${ }^{3}$ Because the incidence of PONV has not changed considerably over the past 10 years, one could argue that this cost currently eclipses the $\$ 2$ million mark. Overall, the annual cost of PONV in the United States is estimated to be several hundred million dollars. ${ }^{1}$

PONV affects the full spectrum of surgical specialties; however, in plastic surgery, a field dependent on patient satisfaction, the effects on patient experience and outcome are strikingly amplified. Nausea and emesis is one of the adverse surgical outcomes patients most desire to avoid and one of the most common reasons for poor patient satisfaction postoperatively. ${ }^{4,5}$ In a published report asking patients to list potential postoperative events in order of undesirability and allocate hypothetical funds to the prevention of these events, patients were willing to allocate a larger percentage toward the prevention of $\mathrm{PONV}^{4,6}$ (Fig. 1).

In addition to making the patient feel subjectively miserable, PONV has important implications for patient procedural outcomes (Table 1). Reports in the literature have established the association of PONV with longer

\footnotetext{
${ }^{1}$ Division of Plastic and Reconstructive Surgery, Northwestern University, Feinberg School of Medicine, Chicago, Illinois.

Address for correspondence and reprint requests: John Y.S. Kim, M.D., Associate Professor, Division of Plastic and Reconstructive Surgery, Northwestern University, Feinberg School of Medicine, 675 North St. Clair Street, Suite 19-250, Chicago, IL 60611.
}

Optimization of Patient Safety in Cosmetic Surgery; Guest Editors, C. Bob Basu, M.D., M.P.H. and Gustavo A. Colon, M.D.

Semin Plast Surg 2006;20:249-256. Copyright (C) 2006 by Thieme Medical Publishers, Inc., 333 Seventh Avenue, New York, NY 10001, USA. Tel: +1(212) 584-4662.

DOI 10.1055/s-2006-951583. ISSN 1535-2188. 


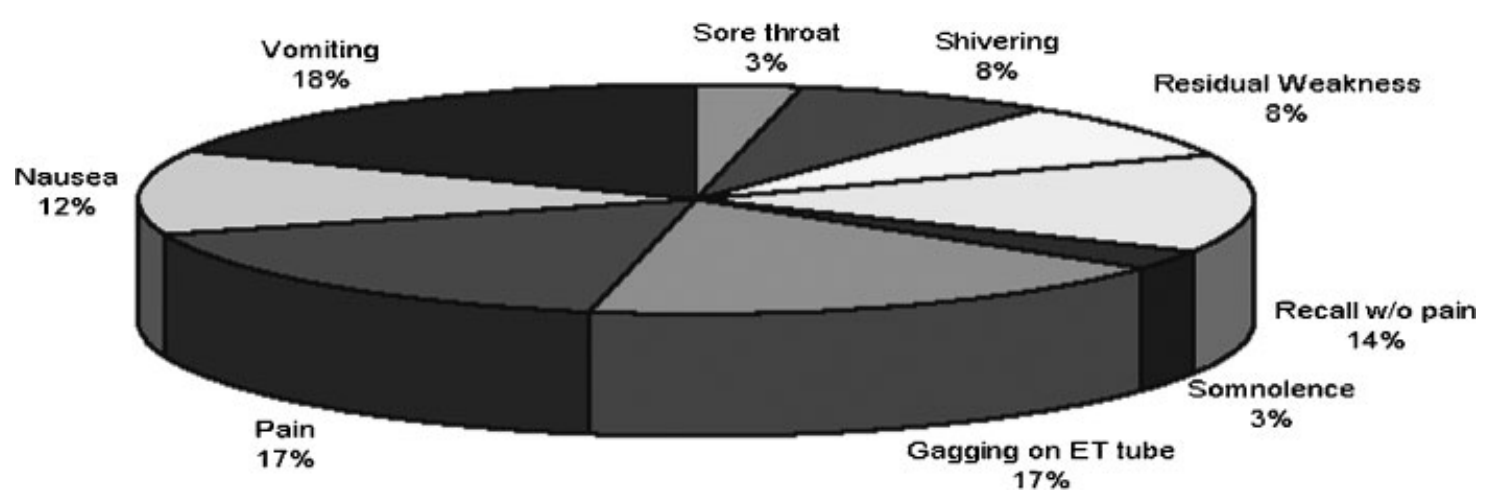

Figure 1 Percentage of patients' hypothetical budget allocated to avoid complications. (From Macario et al. ${ }^{4}$ )

recovery periods and unintended hospital admissions. ${ }^{2}$ In a case series of 300 patients, Marcus et al reported that nausea and vomiting accounted for nearly $73 \%$ of unplanned admissions after plastic surgery procedures ${ }^{2}$ (Table 2). Retching and the act of vomiting can also potentially lead to hematoma formation, ${ }^{7-9}$ suture and wound dehiscence, and aspiration. ${ }^{10}$

\section{ETIOLOGY OF POSTOPERATIVE NAUSEA AND VOMITING}

The etiology of PONV is unknown. Multiple anatomic sites are involved in the PONV cascade. The vomiting center, the central control site of nausea and vomiting, is located within the lateral reticular formation of the brainstem. ${ }^{11}$ This center receives inputs from many neuroanatomical sites including the cerebral cortex, cerebellum, vestibular system, visceral afferents via vagal and glossopharyngeal cranial nerves, and the chemoreceptor trigger zone (CTZ). Each site contains multiple receptors specific for at least one of four neurotransmitters: acetylcholine, serotonin, dopamine, and histamine. ${ }^{12}$ Current antiemetic medications target one of these four systems at specific sites within the cascade. Anticholinergics and antihistamines attack the vomiting center, and metoclopramide, phenothiazines, and benzodiazepines affect neural transmission within visceral afferents, the CTZ, and cerebral cortex, respectively. ${ }^{13}$ The 5-hydroxytryptamine $\left(5-\mathrm{HT}_{3}\right)$ serotonin antagonists act upon visceral afferents as well as the CTZ (see earlier). Because no single agent can simultaneously

Table 1 Clinical Consequences of Postoperative Nausea and Vomiting

\begin{tabular}{l} 
Patient discomfort \\
Hematoma formation \\
Wound dehiscence \\
Aspiration \\
Delay in postoperative recovery \\
Unintended hospital admission \\
\hline
\end{tabular}

affect all of the systems, complete elimination of PONV with single-therapy treatment is unlikely.

\section{EPIDEMIOLOGY OF POSTOPERATIVE NAUSEA AND VOMITING}

Several risk factors have been identified that place patients at higher risk for the development of PONV (Table 3). These risk factors can easily be categorized into three distinct groups: patient-related factors, surgical factors, and anesthetic factors. ${ }^{14}$

Female gender is one of the strongest patientspecific predictors, as females are three times more likely to suffer from PONV than their male counterparts. ${ }^{15}$ Nonsmokers are also at increased risk, ${ }^{14,16}$ as well as patients with a history of motion sickness, prior PONV, or history of opioid-induced nausea and vomiting. ${ }^{2,14,15}$ Age, although minor, is also thought to contribute. This age-related risk peaks in the 6- to 16-year-old age group with a gradual decline in adulthood. ${ }^{17-20}$

Table 2 Reasons for Unplanned Admissions after Plastic Surgery

\begin{tabular}{lr}
\hline Nausea and vomiting & $73 \%$ \\
Drowsiness & $20 \%$ \\
Pain & $6 \%$ \\
\hline
\end{tabular}

Adapted from Marcus et al. ${ }^{7}$

Table 3 Identified Risk Factors for Postoperative Nausea and Vomiting

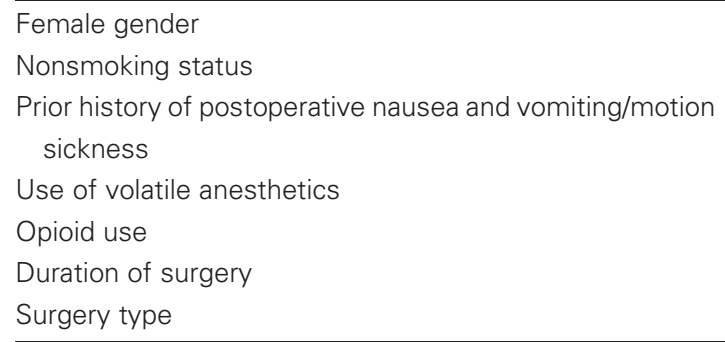




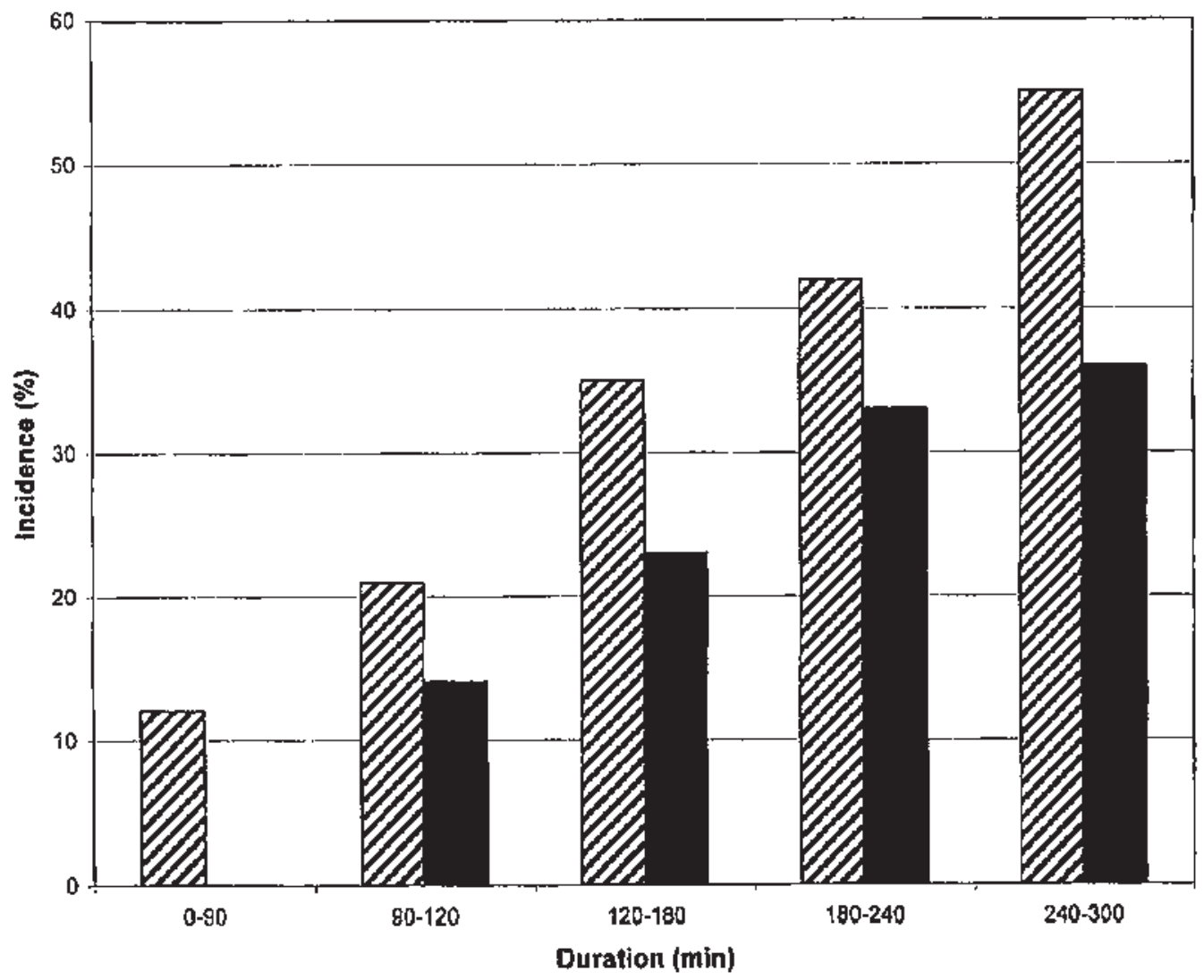

Figure 2 Relationship of surgical duration and the incidence of postoperative nausea and vomiting. The shaded box represents the incidence of nausea and the dark box represents vomiting. (From Marcus et al. ${ }^{2}$ )

The strongest surgical predictor for PONV is related to the duration of surgery, with risk increasing proportionately after 90 minutes $^{2,15}$ (see Fig. 2). One could argue that this effect is directly related to the duration of exposure to anesthetic agents. The type and site of surgery may also play a role; however, large prospective trials have provided some conflicting results. Plastic surgery, inner ear surgery, ophthalmologic surgery, orthopedic surgery, intra-abdominal surgery, and laparoscopy are often cited as the procedures with the highest incidence of PONV. ${ }^{2}$ With regard to plastic surgery, facial rejuvenation procedures confer the greatest risk. $^{2}$

It is well known that patients receiving general anesthesia are at highest risk for developing PONV. ${ }^{21}$ The judicious use of opioid analgesics also plays a role. ${ }^{15}$ Although it is difficult to alter patient-related and surgically related risk factors, anesthetic factors, where appropriate, can be adjusted to decrease baseline risk. For instance, the use of intravenous propofol or conscious sedation for carefully selected patients, instead of volatile inhalational anesthetics, has been proven to reduce PONV. ${ }^{1,22,23}$ Avoidance or limited use of opioid analgesia can also aid preventative efforts. ${ }^{1}$

Reduction in the incidence of PONV requires careful preoperative consideration of risk factors as well as the appropriate use of prophylactic antiemetic drugs. ${ }^{24}$ Risk assessment and stratification should be performed for all patients preoperatively. Risk scoring is easy to use in clinical practice. Apfel et al developed a simplified risk-scoring tool for surgical patients based on four predictors: female gender, history of motion sickness or prior PONV, nonsmoking status, and use of postoperative opioids. Patients were assigned one point for each factor being present. The incidence of PONV for $\mathrm{pa}^{-}$ tients with $0,1,2,3$, and 4 risk factor points was $10 \%$, $21 \%, 39 \%, 61 \%$, and $79 \%$, respectively. ${ }^{25}$ In this scoring system, to obtain the best overall sensitivity and specificity, patients with a risk score of 0 are classified as low risk, 1 to 2 moderate risk, and 3 or more as high risk. ${ }^{26}$ Studies have shown that prophylactic treatment with antiemetic drugs is efficacious and cost effective as long as the patient is at moderate to high risk for developing PONV. ${ }^{13,27,28}$

\section{ANTIEMETIC PROPHYLAXIS OF POSTOPERATIVE NAUSEA AND VOMITING}

The antiemetics most commonly used for PONV prophylaxis include ondansetron, droperidol, promethazine, dexamethasone, prochlorperazine, scopolamine, and 
Table 4 Antiemetics and their Recommended Dosages for Postoperative Nausea and Vomiting Prophylaxis

\begin{tabular}{|c|c|c|}
\hline Antiemetic & Dose & \\
\hline Ondansetron & $4 \mathrm{mg}$ IV & Prior to the end of surgery \\
\hline Droperidol & $0.625 \mathrm{mg} \mathrm{IV}$ & Prior to the end of surgery \\
\hline Promethazine & $12.5 \mathrm{mg} \mathrm{IV}$ & Prior to the end of surgery \\
\hline Prochlorperazine & $5 \mathrm{mg} \mathrm{IV}$ & Prior to the end of surgery \\
\hline Dexamethasone & $5 \mathrm{mg} \mathrm{IV}$ & Prior to induction \\
\hline Metoclopramide & $10 \mathrm{mg}$ IV & After induction \\
\hline Scopolamine & $\begin{array}{l}\text { Transdermal } \\
\text { patch }\end{array}$ & $\begin{array}{l}\text { Prior evening or } 4 \text { hours } \\
\text { prior to end of surgery }\end{array}$ \\
\hline Aprepitant & 40 mg PO & 1-3 hours prior to Induction \\
\hline
\end{tabular}

metoclopramide $^{10,29}$ (Table 4). Multiple published reports suggest ondansetron as the superior antiemetic, offering improved efficacy as well as a relatively negligible side effect profile. ${ }^{2,30-34}$ The only disadvantage is its increased cost compared with other options.

Ondansetron produces its antiemetic effect through antagonism of a specific serotonin receptor, the $5-\mathrm{HT}_{3}$ receptor, within visceral afferents and the CTZ. The recommended prophylactic dose of ondansetron is typically a single 4-mg dose given intravenously immediately before the induction of anesthesia. ${ }^{2,35}$ The dose was selected based on pooled data from studies suggesting $4 \mathrm{mg}$ as the optimal prophylactic dose. ${ }^{36}$ The timing of ondansetron administration has been called into question. Studies comparing dosing prior to induction versus 30 minutes before the end of surgery have reported increased efficacy with end-of-surgery administration. ${ }^{24,36}$ The likely reason for such results is the relatively short half-life of the drug. In cases lasting longer than 4 hours, preinduction users may gain improved prophylaxis by administering an additional dose prior to the end of the operation. Ondansetron is also available in an elixir and an orally dissolving tablet form that can be offered as rescue treatment postoperatively to patients with swallowing difficulties or lacking intravenous access. In a report by Rohrich et al, the efficacy of prophylactic ondansetron was further enhanced with the adjunct use of postoperative ReliefBand ${ }^{\circledR}$ (Woodside Biomedical Systems, Carlsbad, CA) acupoint stimulation. $^{37}$

Kovac recently addressed other controversies involving the $5-\mathrm{HT}_{3}$ inhibitor class. Little difference in efficacy has been reported between the various $5-\mathrm{HT}_{3}$ inhibitors. Because of interaction with cardiac ion channels, there is a reported theoretical risk of cardiac conduction abnormalities with the use of $5-\mathrm{HT}_{3}$ inhibitors. Highest concern is with dolasetron and tropisetron because of their metabolism by the hepatic enzyme CYP2D6 and the potential for drug-drug interactions. ${ }^{38}$

Droperidol is thought to produce antiemetic effects through the antagonism of central dopamine receptors. ${ }^{39}$ In addition to dopamine antagonism, droperidol has $\alpha$ blocking activity, which can lead to hypotension and extrapyramidal side effects. The Food and Drug Administration (FDA) placed a "black box" warning on the use of droperidol because of the potential for cardiac dysrhythmias including QT prolongation and torsades de pointes. This warning is based on nine case reports of sudden cardiac death after the perioperative administration of droperidol. ${ }^{38}$ After publication of these case reports, many hospitals omitted droperidol from their formulary, and thus its use has become less common. In head-to-head clinical studies, droperidol has similar efficacy to ondansetron but is used less frequently because of its side effect profile. ${ }^{30,40-42}$ The recommended prophylactic dose is $0.625 \mathrm{mg}$ intravenously (IV). ${ }^{29} \mathrm{It}$ is most effective when administered at the end of surgery.

The phenothiazines, promethazine and prochlorperazine, are antihistamines as well as dopamine receptor antagonists. The main site of action is within the CTZ. ${ }^{10}$ Despite proven antiemetic efficacy, the use of phenothiazines in ambulatory surgery as first-line prophylactic agents is limited because of their sedative effect. Additional side effects include dizziness and dry mouth. The recommended prophylactic dosages for promethazine and prochlorperazine are $12.5 \mathrm{mg}$ IV and $5 \mathrm{mg}$ IV, respectively. ${ }^{29}$ They are typically administered at the end of surgery. Habib and Gan reported on the efficacy of promethazine as a rescue antiemetic for patients suffering from PONV despite prophylaxis with ondansetron or droperidol. ${ }^{43}$ Promethazine was significantly more effective than a second dose of the prophylactic agent.

The exact mechanism of action for dexamethasone is not entirely known, but it is believed to be related to anti-inflammatory action within the gut leading to serotonin reduction. ${ }^{38}$ Dexamethasone is most effective as prophylaxis when administered prior to induction at a dosage of 8 to $10 \mathrm{mg} \mathrm{IV.}{ }^{29}$ The side effect profile of dexamethasone can include poor wound healing, wound infection, and adrenal suppression. As with other corticosteroids, these side effects more commonly occur with long-term usage.

Scopolamine is an anticholinergic agent with peripheral and central action primarily within the vomiting center. ${ }^{38} \mathrm{~A}$ clinical investigation of transdermal scopolamine involving 23 trials and 979 patients reported a reduction in the risk of $\mathrm{PONV}$ in patients receiving scopolamine; however, this reduction in incidence was at the cost of side effects, most commonly blurry vision, agitation, and dry mouth. ${ }^{38}$ Widespread use of scopolamine may be limited by concerns over the development of side effects. A potential role as an antiemetic administered with patient-controlled analgesia may exist. ${ }^{44}$ If used as prophylaxis, the scopolamine patch is often applied the evening prior or 4 hours before the end of surgery. ${ }^{29}$ 
Metoclopramide is frequently used as an antiemetic because of its action on gut motility and lower esophageal sphincter tone. Metoclopramide also acts as a dopamine antagonist peripherally and centrally in the CTZ. Despite its wide usage, studies have failed to report significant efficacy in preventing PONV. ${ }^{38}$ The recommended prophylactic dosage is $10 \mathrm{mg}$ IV administered just after induction.

Patients at high risk for nausea and vomiting based on previous history of PONV with anesthesia or narcotic use can benefit from a multidrug regimen, including ondansetron, metoclopramide, promethazine, and Decadron.

In July 2006, a new antiemetic was approved by the FDA, which acts by yet a different mechanism. Aprepitant (Emend ${ }^{\circledR}$, Merck \& Co., Whitehouse Station, $\mathrm{NJ}$ ) is a selective antagonist of human substance $\mathrm{P} /$ neurokinin 1 (NK1) receptors. It has little effect on the primary neurotransmitter systems targeted by current antiemetic therapy. The FDA approval was based on two multicenter, randomized, double-blind trials of aprepitant matched head to head against ondansetron. Both studies reported superior efficacy with aprepitant in the prevention of nausea and vomiting through 24 and 48 hours postoperatively. ${ }^{45}$ The administered dosages were 40 and $125 \mathrm{mg}$ by mouth (PO), within 1 to 3 hours prior to surgery. No significant difference was reported between the 40 and $125 \mathrm{mg}$ doses. The recommended dosage for PONV prophylaxis is $40 \mathrm{mg}$ $\mathrm{PO}$ in $50 \mathrm{~mL}$ of water within 3 hours of surgery. The greatest concern about adverse events is related to aprepitant's effect on the hepatic enzyme CYP3A4. Patients with liver disease, on certain chemotherapeutic medications, or taking drugs that are metabolized by the CYP3A4 enzyme, including Coumadin and oral contraceptive pills (OCPs), should use caution when taking aprepitant as drug-drug interactions may occur. Women who are taking OCPs while taking aprepitant and for 1 month afterward should use a backup form of contraception. Other common side effects include fatigue, nausea, hiccups, constipation, diarrhea, and anorexia. The current role of aprepitant in ambulatory surgery is not entirely known; however, preliminary investigations reveal great potential for safe and effective PONV prevention.

\section{RISK ASSESSMENT}

In 2003, Gan et al reported evidence-based consensus guidelines for the management of PONV. These guidelines helped to establish a useful algorithm that follows a multimodal approach from identification to management of high-risk patients (Table 5). ${ }^{29}$

The first step in the algorithm is to identify patients at increased for PONV. Risk assessments and stratification, such as Apfel's simplified risk scoring
Table 5 Algorithm for Risk Identification and Management of Postoperative Nausea and Vomiting

\begin{tabular}{|c|c|}
\hline 1. & $\begin{array}{l}\text { Identify patients at increased risk for } \\
\text { postoperative nausea and vomiting } \\
\text { Risk assessment and stratification }\end{array}$ \\
\hline 2. & $\begin{array}{l}\text { Reduce baseline risk } \\
\text { Avoid general anesthesia } \\
\text { Minimize opioid use } \\
\text { Adequate hydration } \\
\text { Intraoperative supplemental oxygen }\end{array}$ \\
\hline 3. & $\begin{array}{l}\text { Antiemetic prophylaxis } \\
\text { Moderate risk: Monotherapy or combination } \\
\text { antiemetic therapy recommended } \\
\text { High risk: Combination antiemetic } \\
\text { therapy recommended }\end{array}$ \\
\hline
\end{tabular}

system, are a quick and easy way to establish baseline preoperative risk. Once this risk is established, the next appropriate step is to reduce baseline risk factors, if clinically possible. Gan et al reported several strategies to accomplish this task, including the use of regional anesthesia or propofol instead of volatile anesthetics, minimizing intraoperative and postoperative use of opioids, use of intraoperative supplemental oxygen, and adequately hydrating the patient. ${ }^{29}$ Nonpharmacologic therapies, such as acupoint stimulation, acupressure, or acupuncture, may also be considered.

Patients at high risk for PONV should receive antiemetic prophylaxis with of the antiemetic drugs mentioned previously. If there is significant risk, combination therapy with two or three drugs from different classes can be used. Effective multidrug regimens include the combination of ondansetron with droperidol, dexamethasone, or promethazine. If nausea and vomiting persist despite prophylaxis, rescue antiemetics can be given. For single-drug prophylaxis, rescue therapy with promethazine, an additional dose of ondansetron, or another $5-\mathrm{HT}_{3}$ inhibitor can be administered. ${ }^{38,43}$ If combination prophylaxis fails, antiemetics from a different class should be considered.

\section{POSTOPERATIVE NAUSEA AND VOMITING AND PLASTIC SURGERY}

In 2004, nearly 1.7 million cosmetic surgery procedures were performed in the United States. ${ }^{46}$ The overall incidence of PONV in plastic surgery is $\sim 35 \% .{ }^{10}$ There are four statistically significant factors that place plastic surgery patients at greatest risk for developing PONV: female gender, use of general anesthesia, postoperative opioid use, and duration of surgery. ${ }^{2,10}$ In plastic surgery, unlike other surgical fields, patients' satisfaction is based on overall experience as much as the final result. Thus, the prevention of PONV can positively influence patients' experience, leading to greater satisfaction and 
improved outcomes. Steely et al, in 2004, reported on the efficacy of PONV prophylaxis in plastic surgery. In a case series of 143 plastic surgery patients, the incidence of PONV was reduced to $3 \%$ with a multitherapeutic regimen. The antiemetic regimen included ondansetron $4 \mathrm{mg}$ IV at induction followed by metoclopramide $10 \mathrm{mg}$ IV. In facial surgery cases, patients also received dexamethasone $10 \mathrm{mg}$ IV. Patients received liberal IV hydration throughout the case and gastric suctioning at the completion of the procedure. Prior to extubation, promethazine $25 \mathrm{mg}$ intramuscularly was administered. In cases lasting more than 4 hours, patients were redosed with ondansetron. ${ }^{10}$ The results from this prospective study clearly define the impact that antiemetic prophylaxis can have in plastic surgery. Although the exact prophylactic regimen may vary between institutions, the principles of risk assessment, stratification, and prophylaxis remain the same. Thorough evaluation of patient's risk preoperatively and the armamentarium of antiemetic medications will enable the plastic surgeon to play an active role in minimizing PONV and improving overall surgical outcome.

\section{ACKNOWLEDGMENTS}

The authors of this article have no commercial or current research relationship with any of the drug manufacturers or Woodside Biomedical Systems.

\section{REFERENCES}

1. Apfel CC, Korttila K, Abdalla M, et al. A factorial trial of six interventions for the prevention of postoperative nausea and vomiting. N Engl J Med 2004;350:2441-2451

2. Marcus JR, Few JW, Chao JD, Fine NA, Mustoe TA. The prevention of emesis in plastic surgery: a randomized, prospective study. Plast Reconstr Surg 2002;109:24872494

3. Hirsch J. Impact of postoperative nausea and vomiting in the surgical setting. Anaesthesia 1994;49:30-33

4. Macario A, Weinger M, Carney S, Kim A. Which clinical anesthesia outcomes are important to avoid? The prospective patients. Anesth Analg 1999;89:652-658

5. Myles PS, Williams DL, Hendrata M, et al. Patient satisfaction after anesthesia and surgery: results of a prospective survey of 10811 patients. Br J Anaesth 2000;84:6-10

6. Gan T, Sloan F, Dear G, et al. How much are patients willing to pay to avoid postoperative nausea and vomiting? Anesth Analg 2001;92:393-400

7. Marcus JR, Tyrone JW, Few JW, Fine NA, Mustoe TA. Optimization of conscious sedation in plastic surgery. Plast Reconstr Surg 1999;104:1338-1345

8. Dingman RO. Severe bleeding during and after face-lifting operations under general anesthesia. Plast Reconstr Surg 1972;50:608

9. Thompson DP, Ashley FL. Face-lift complications: a study of 922 cases performed in a 6-year period. Plast Reconstr Surg 1978;61:40-49
10. Steely RL, Collins DR, Cohen BE, Bass K. Postoperative nausea and vomiting in the plastic surgery patient. Aesthetic Plast Surg 2004;28:29-32

11. Williams KS. Postoperative nausea and vomiting. Surg Clin North Am 2005;85:1229-1241

12. Watcha MF, White PF. Postoperative nausea and vomiting. Its etiology, treatment, and prevention. Anesthesiology 1992; 77:162-184

13. Tortorice PV, O'Connell MB. Management of chemotherapy-induced nausea and vomiting. Pharmacotherapy 1990;10:129-145

14. Stadler M, Bardiau F, Seidel L, et al. Difference in risk factors for postoperative nausea and vomiting. Anethesiology 2003;98:46-52

15. Apfel CC, Roewer N. Risk assessment of postoperative nausea and vomiting. Int Anesthesiol Clin 2003;41:13-32

16. Cohen MM, Duncan PG, DeBoer DP, et al. The postoperative interview: assessing risk factors for nausea and vomiting. Anesth Analg 1994;78:7-16

17. Sadhasivam S, Shende D, Madan R. Prophylactic ondansetron in prevention of postoperative nausea and vomiting following pediatric strabismus surgery: a dose-response study. Anesthesiology 2000;92:1035-1042

18. Gurler T, Celik N, Totan S, Songur E, Sakarya M. Prophylactic use of ondansetron for emesis after craniofacial operations in children. J Craniofac Surg 1999;10:4548

19. Rose JB, Watcha MF. Postoperative nausea and vomiting in paediatric patients. Br J Anaesth 1999;83:104-117

20. Stubbs TK, Saylors S, Jenkins M, et al. Pediatric patients experiencing postoperative nausea and vomiting after burn reconstruction surgery: an analysis. J Burn Care Rehabil 1999;20:236-238

21. Apfel CC, Kranke P, Papenfufl T, et al. Volatile anaesthetics may be the main cause for early but not delayed postoperative nausea and vomiting: a randomized control trial of factorial design. Br J Anaesth 2002;88:659668

22. Unlugenc H, Guler T, Gunes Y, Isik G. Comparative study of the antiemetic efficacy of ondansetron, propofol, and midazolam in the early postoperative period. Eur J Anaesthesiol 2003;20:668-673

23. Hasen KV, Samartzis D, Casas LA, Mustoe TA. An outcome study comparing intravenous sedation with midazolam/fentanyl (conscious sedation) versus propofol infusion (deep sedation) for aesthetic surgery. Plast Reconstr Surg 2003;112:1683-1689

24. Watcha MF. The cost-effective management of postoperative nausea and vomiting [editorial; comment]. Anesthesiology 2000;92:931-933

25. Apfel CC, Laara E, Koivuranta M, Greim CA, Roewer N. A simplified risk score for predicting postoperative nausea and vomiting. Anesthesiology 1999;91:693-700

26. Apfel CC, Kranke P, Eberhart J. Comparison of surgical site and patient's history with a simplified risk score for the prediction of postoperative nausea and vomiting. Anaesthesia 2004;59:1078-1082

27. Tang J, Wang B, White PF, et al. The effect of timing of ondansetron administration on its efficacy, cost-effectiveness, and cost-benefit as a prophylactic antiemetic in the ambulatory setting. Anesth Analg 1998;86:274-282

28. Sadhasivam S, Saxena A, Kathirvel S, et al. The safety and efficacy of prophylactic ondansetron in patients undergoing 
modified radical mastectomy. Anesth Analg 1999;89:13401345

29. Gan TJ, Meyer T, Apfel CC, et al. Consensus guidelines for managing postoperative nausea and vomiting. Anesth Analg 2003;97:62-71

30. Domino KB, Anderson EA, Polissar NL, Posner KL. Comparative efficacy and safety of ondansetron, droperidol, and metoclopramide for preventing postoperative nausea and vomiting: a meta-analysis. Anesth Analg 1999;88:13701379

31. Dabbous A, Itani M, Kawas N, et al. Post-laparoscopic vomiting in females versus males: comparison of prophylactic antiemetic action of ondansetron versus metoclopramide. JSLS 1998;2:273-276

32. Malins AF, Field JM, Nesling PM, Coope GM. Nausea and vomiting after gynaecological laparoscopy: comparison of premedication with oral ondansetron, metoclopramide, and placebo. Br J Anaesth 1994;72:231-233

33. Paxton LD, McKay AC, Mirakhur RK. Prevention of nausea and vomiting after day case gynaecological laparoscopy: a comparison of ondansetron, droperidol, metoclopramide, and placebo. Anaesthesia 1995;50:403-406

34. Tang J, Watcha MF, White PF. A comparison of costs and efficacy of ondansetron and droperidol as prophylactic antiemetic therapy for elective outpatient gynecologic procedures. Anesth Analg 1996;83:304-313

35. Barbosa MVJ, Nahas FX, Ferreira LM, et al. Ondansetron for the prevention of postoperative nausea and vomiting: which is the best dosage for aesthetic plastic surgery. Aesthetic Plast Surg 2004;28:33-36

36. Sun R, Klein KW, White PF. The effect of timing of ondansetron administration in outpatients undergoing otolaryngologic surgery. Anesth Analg 1997;84:331336
37. White PF, Hamza MA, Recart A, et al. Optimal timing of acustimulation for antiemetic prophylaxis as an adjunct to ondansetron in patients undergoing plastic surgery. Anesth Analg 2005;100:367-372

38. Kovac AL. Prophylaxis of postoperative nausea and vomiting: controversies in the use of serotonin 5-hydroxytryptamine subtype 3 receptor antagonists. J Clin Anesth 2006;18:304318

39. Cameron D, Gan TJ. Management of postoperative nausea and vomiting in ambulatory surgery. Anesthesiol Clin North Am 2003;21:347-365

40. Lim BS, Pavy TJ, Lumsden G. The antiemetic and dysphoric effects of droperidol in the day surgery patient. Anaesth Intensive Care 1999;27:371-374

41. Tramer MR, Walder B. Efficacy and adverse effects of prophylactic antiemetics during patient-controlled analgesia therapy. Anesth Analg 1999;88:1354-1361

42. Tang J, Chen X, White PF, et al. Antiemetic prophylaxis for office-based surgery. Anesthesiology 2003;98:293-298

43. Habib AS, Gan TJ. The effectiveness of rescue antiemetics after failure of prophylaxis with ondansetron or droperidol: a preliminary report. J Clin Anesth 2005;17: $62-65$

44. Williams OA, Clarke FL, Harris RW, et al. Addition of droperidol to patient-controlled analgesia: effect on nausea and vomiting. Anaesthesia 1993;48:881-884

45. Approves FDA. EMEND ${ }^{\circledR}$ (aprepitant), Merck's Antiemetic Therapy, for the Prevention of Postoperative Nausea and Vomiting. Available at: http://www.emend. com/aprepitvant/emend/hcp/ponv/index.jsp. Accessed July 31, 2006

46. American Society of Plastic Surgeons. Available at: http:// www.plasticsurgery.org/new_room/press_releases/2004Overall-Statistics.cfm. Accessed July 15, 2006 